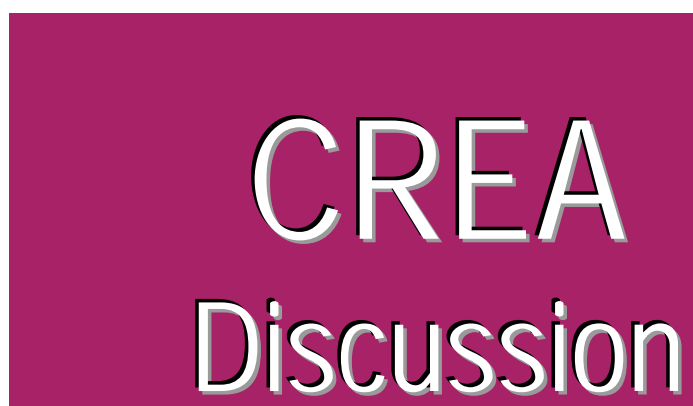
Paper 2015-14 Economics

Center for Research in Economics and Management University of Luxembourg

\title{
The role of networks for migration flows: an update
}

available online : http://wwwfr.uni.Iu/recherche/fdef/crea/publications2/discussion_papers

Michel Beine, CREA, Université du Luxembourg

July, 2015

For editorial correspondence, please contact: crea@uni.lu

University of Luxembourg

Faculty of Law, Economics and Finance

$162 \mathrm{~A}$, avenue de la Faïencerie

L-1511 Luxembourg

The opinions and results mentioned in this paper do not reflect the position of the Institution 


\title{
The role of networks for migration flows: an update
}

\author{
Michel Beine* \\ First version: July 2015. This revised version: February 2016
}

\begin{abstract}
This paper covers the literature on the role of migrants networks in explaining aggregate migration flows between countries. We first provide a small review of the literature and the issues at stake. We then provide an update of the estimates of the network elasticities using data on migration stocks and flows extracted from Ozden et al. (2011). Using a micro-founded gravity model, we estimate the network elasticities and discuss the key driving mechanisms explaining their size as well their variation across categories of destination countries and over time. We account for the issue of multilateral resistance to migration and obtain estimates that are in line with the ones documented previously in the literature. We find that the role of networks in attracting migrants has increased after the 70's. As a way to shed some light on this result, we emphasize the specific role of family immigration policies. To that aim, we cover briefly the recent experience of a set of destination countries to highlight the importance of these policies in explaining part of the observed network elasticities.
\end{abstract}

JEL Classification: F22, O15, R11, R15

Keywords:International migration, Network effects, Elasticity macroestimates, Diasporas.

\section{Introduction}

The determinants of international migration in both origin and destination countries have been recently analyzed from a lot of different perspectives. A large literature has tried to identify the various determinants of international migration (see Beine et al., 2015a for a recent survey). Among these determinants, the existence of a network of previous migrants from the same country turns out to be a key factor in explaining the size and the patterns of international migration flows. The role of a diaspora as an attraction mechanism of future migrants of the same country has been emphasized quite early by researchers in social sciences, as reflected by the early contribution of Massey et al. (1993).

The recent literature has tried to deepen our understanding the role of these networks in terms of subsequent migration. Micro and macro studies have combined their

${ }^{*}$ CREA, University of Luxembourg, IRES, CREAM, IZA and CES-Ifo, michel.beine@uni.lu 
respective approaches to shed some light on the key mechanisms behind the global network effect. Empirical studies have tried to provide estimates of these network effects, either in terms of a global effect or in terms of the various components of these effects. Micro-estimates using individual data have been provided, often based on specific migration corridors. Macro-estimates using measures of aggregate flows and cross-country data provide a complementary view and allow to assess important components of the network effect such as the role of family reunification policies. While each approach has its own merits and limitations, the assessment of the strengths of the network effect and its components remains an important task since networks turn out to be one of the major factors explaining the size and the pattern of migration flows across countries.

To that aim, this paper focuses on the network effect in terms of international migration. It reviews quickly the recent existing literature on the network effect, emphasizing the need for both micro and macro approaches. Then it provides an update of the macro estimates using the panel database of Ozden et al. (2011). The panel dimension allows us to refine the previous macro estimates in different directions. First, the variation over time and across countries allows us to estimate network elasticities by accounting for all dimensions of the issue of multilateral resistance to migration that characterizes the use of dyadic data (Bertoli and Fernandez-Huerta-Moraga, 2013). Second, the variation over time allows to characterize the evolution of the network elasticity. This can be in turn related to the evolution of the two main components of the network effect at the macro level, namely the assimilation effect and the policy effect (Beine et al., 2015b). Finally, the comprehensive coverage of the data in terms of origins and destinations allows us to reestimate the elasticity across categories of destinations.

The main findings can be summarized as follows. First, an explicit specification allowing to fully control for multilateral resistance of migration does not alter significantly the estimate of the global network elasticity. Second, in line with previous analysis emphasizing the role of the education level, we find that the network effect prevailing in developed countries that host a higher proportion of skilled migrants is lower than in less developed countries. Finally, we find that the network elasticity has tended to increase between the 1960-1980 period and the 1980-2000 decades. This can be partly ascribed to more generous immigration policies in terms of family reunification. A quick coverage of a set of important destination countries in terms of these policies confirms this interpretation.

The paper is organized as follows. Section 2 covers quickly some of the existing literature on the network effect. Section 3 clarifies the micro-foundations of the estimated specification. Section 4 discusses the econometric approach, reports the results and provides a discussion of the main findings. Section 5 concludes.

\section{A quick review of the literature}

The determinants of international migration in both origin and destination countries have been recently analyzed from different perspectives. A large literature has tried to identify the various determinants of international migration (see Beine, et al., 2015a for a recent survey). The possible explanations of the magnitude and the pattern of the migration flows are not mutually exclusive. The Random Utility Maximization framework (Grogger 
and Hanson, 2011, Beine et al., 2011, Anderson, 2011) allows to identify in a theoretical way the key factors. These include among others wage differentials, migration costs and push and pull factors. Empirically, the impact of wage differential has been estimated in a couple of papers such as Grogger and Hanson (2011), Bertoli and Fernandez-HuertasMoraga (2015)and Beine et al. (2013). The migration costs include various components such as distance, immigration policy, linguistic differences between the origin and the destination. They are also related to the the network effect. Push factors include factors prevailing in the origin countries and inducing natives to leave the country. They include for instance, demographic factors, political conditions and institutional quality (Ariu et al., 2014) or environmental shocks (Beine and Parsons, 2015), although the empirical importance of the latter ones is still subject to discussion. Pull factors include many factors such as unilateral and immigration policies (see for instance Czaika and Parsons, 2015) and bilateral ones (Bertoli and Fernandez-Huertas-Moraga,2015).

The presence of a diaspora is also a key determinant of migration flows. The role of a diaspora as an attraction mechanism of future migrants of the same country has been emphasized quite early by researchers in social sciences, as reflected by the early contribution of Massey et al. (1993). The so-called network effect adds significant explanatory power of migration flows with respect to the influence of the other factors mentioned above (Beine et al., 2011). Without accounting for the impact of a diaspora and relying on traditional factors such as distance, linguistic proximity or colonial links, it is cumbersome to explain the observed bilateral international migration flows such as the contemporaneous Turkish immigration flows to Germany (about 57000 new immigrants in 2010).

The network effect in international migration might be defined broadly as the aggregate impact of an existing diaspora in a given area on the probability of subsequent inflows of the migrants coming from the same origin country. This aggregate impact might be disentangled into three main components. The first component relates to the pure decrease in migration costs induced by the existing migrants. The diaspora can help prospective migrants to adapt more easily to the new constraints associated to the destination. Assistance in terms of housing or linguistic support to the new migrants fall into that category. Also, financial assistance in case of adverse developments might provide an implicit insurance scheme. While it is not easy to identify the precise channels through which migration costs decrease, the microeconomic literature using individual data provides some evidence of such effects, as reflected by the early contribution of McKenzie and Rapoport (2010). Comola and Mendola (2015) provides evidence that networks of Sri Lankan immigrants living in Milan provides assistance in terms of accommodation and credit. Giuletti et al. (2014) emphasize the complementarity of weak ties and strong ties between the migrants and the network in favouring migration in China.

A second related component pertains to the benefits that the network provides to the migrants. The main benefit stands in terms of expected income. Migrants network provide useful information about job opportunities. They raise the probability for new migrants to have access to the labour market. Network can also be useful in signalling in which sectors migrants can find the best jobs in terms of wages and work conditions. Munshi (2003) for instance studies job networks among Mexican migrants in the U.S. and shows that established migrants help newcomers to be employed and to hold an higher paying occupation. Comola and Mendola (2014) also provide some similar evidence 
in terms of employment rates of Sri Lankan immigrants. At a macro level, these two components represent one aggregate network effect which is not related to immigration policy. This applies also for instance to internal migration. The first theoretical analysis of that kind is due to Carrington and Detagriache (1996) who use a dynamic model allowing to explain the increased intensity of migration of black American workers from US Southern states to Northern states during the 1930's.

It should be emphasized that networks can also have a set of various effects on top of the mere attraction mechanism. First, it is well known that networks in some countries can be concentrated on specific segments of the labour markets. For instance, the network of Portuguese workers in Luxembourg is highly concentrated in the residential building sector. Using US regional data, Patel and Vella (2013) show that there is a strong network effect in terms of professional occupations, with positive impact in terms of earnings for new immigrants who choose the most common occupation of their compatriots. Focusing on ethnic networks, Kerr and Mandorff (2015) find similar results. On the other hand, network can lead to significant occupational downgrading for newcomers. ${ }^{1}$ Networks tend also to influence the skill composition of the migration flows. Since unskilled migrants tend to rely more on diasporas at destination, larger networks tend to attract proportionely more unskilled immigrants. This theoretical prediction is highly supported in teh empirical literature. ${ }^{2}$ Networks also tend to reduce uncertainty related to many migration outcomes (jobs, compliance with regulations at destinations, ...). Therefore, larger networks can attract more risk adverse individuals, which can in turn have important economic consequences in terms of entrepeneurship or investment at destination. ${ }^{3}$ This reduced uncertainty is induced by information flows that follow different channels. ${ }^{4}$ While such phenomena are important, we disregard these effects in the current paper and concentrate on the size of the aggregate assimilation effect of the network.

The last component is the one which is related to immigration policy and in particular to family reunification policies. Jasso and Rosenzweig $(1986,1989)$ first provide for the US evidence of migration multipliers. They show that each 100 additional migrants of one particular origin country raised during the 1970's the inflow of new immigrants from that country in the US by about 70. Additional evidence has been brought by Bin (2007). Of course these numbers are likely to differ across destination countries and over time since family reunification policies tend to be nationally defined and revised on a regular basis.

At a macro level, the estimated network effect using gravity models of international migration flows is the global effect, i.e. the sum of the three components. While the macro

\footnotetext{
${ }^{1}$ See for instance Mahuteau and Junankar (2008) using longitudinal survey data of second cohort immigrants in Australia. Simon et al. (2014) provide econometric evidence of a negative effect of workers networks on the occupational status of immigrants in Spain and a significant downgrading effect with respect to the professional status in the origin country before migration.

${ }^{2}$ See Beine et al., 2011 at a macro level for instance.

${ }^{3}$ See Umblijs (2012) for evidence in favour of that hypothesis based on German data.

${ }^{4}$ See for instance Batista and Narciso (2013) who provide evidence in favour of increased flows of remittances through better information on the use of the money sent back. Using migration data of Tongan potential emigrants to New Zealand and relying on a natural experiment, McKenzie et al. (2013) show that family networks can provide inaccurate information about earnings at destination in order to moderate remittance demands.
} 
literature faces some problems of identification that can be more easily circumvented in micro studies, the main advantage over micro studies is to account for the role of immigration policies in shaping the network effect. Using cross-section data of the 1990's, Beine et al. (2011) obtain an estimated elasticity of about 0.7, i.e. each increase of $10 \%$ in the existing migrants stock triggers an increase of around $7 \%$ in the flow of new migrants from their origin country within the next decade. This elasticity is higher for unskilled migrants (0.8) than for skilled ones (0.6). Using data on US immigration, Beine et al. (2015b) get a slightly higher elasticity (around 1), which is consistent with the migration multiplier of Jasso and Rosenzweig (1988). Using panel data spanning migration flows between 1960 and 2000, Beine and Parsons (2015) also account for the network effect and get slightly lower but highly significant estimates around 0.4. Finally, Beine et al. (2015b) provide a identification strategy to disentangle the global effect into a pure network effect (the two first components following our taxonomy) and the one going through immigration policy (the third component). To that aim, they make use of the distinction between global networks and local ones (using the metropolitan area definition). They show that about 75 percents of the global effect is due to the pure network effect while the rest is due to the family reunification policy. This proportion nevertheless varies with the education level of the migrants.

As reviewed by Munshi (2014), the econometric identification of the network effect is not an easy task. The OLS estimation of models of migration flows leads to biased coefficients of the network effect. One of the main sources of the bias is the occurrence of omitted variables that are both correlated with the migrants network and the immigration flows. Common unobserved factors such as cultural proximity between countries can drive both the formation of migrants networks and current bilateral migration flows. Depending on the sign and the size of the correlation between these unobserved factors and the network, the use of simple OLS models might result in some biased estimates of the typical network elasticities. For instance, if the omitted factor is cultural proximity - which is positively correlated both with the network and with the contemporaneous flow-, the estimated OLS elasticity will be overestimated.

A traditional solution to that issue is to use a classical instrumental variable approach. In that context, a suitable instrument is a variable that is a good predictor of the size of the migrants network at destination and which is uncorrelated with the dependent variable. A successful strategy is to find origin or destination specific variables that are associated to the network and uncorrelated with the dependent variable at stake. A classical example is the one of Munshi (2003) that uses rainfall variation in Mexican regions that are associated with the size of the migrants network in the US. The use of that type of variable is easier in micro studies that focus on a specific migration corridor. In macro analyses, it is more cumbersome to find suitable instruments that are either origin specific (push factor of the network) or destination specific (pull factors of the network) and that predict the size of the network for a sufficient number of country pairs. An exception to that rule is however provided by Beine et al. (2011) who use guest worker programs that were initiated in a set of destination countries and ended up in the 70's. These programs were good predictors of the contemporaneous networks but are uncorrelated with the subsequent migration flows.

The use of panel data with fixed effects also provides a good way to deal with the issue of omitted factors that is the main source of the endogeneity of the network effect. By 
including a set of fixed effects, the panel estimation wipes out a large number of omitted factors that could be correlated with the network. ${ }^{5}$ This ensures that the estimated network elasticity are less subject to significant biases. In this paper, we follow that strategy and reestimate the network elasticity for a large set of origin and destination countries over the 1960-2000 period. This in turn allows to include a rich set of fixed effects such as origin-time fixed effects and destination-time fixed effects. These fixed effects absorb a significant share of the variation of the bilateral migration flows and make sure that what we ascribe to the role of migrants network is not mainly driven by other factors. We will follow this strategy in the update of the estimation of the network elasticities that we provide below.

\section{Microfoundations of the network effect in gravity models}

As reviewed by Beine et al. (2015a), micro-founded gravity models of migration offer a suitable framework to identify the role of the various determinants, including the network effect. Beine et al. (2011) for instance derive a model using the usual random income maximisation (RUM) approach that has become the standard theoretical reference point for any serious macro empirical investigation of the determinants of international migration.

In the RUM approach, individual agents choose the optimal destination based on the comparison of the utility level associated to each location choice. The utility of an individual associated to the fact that he stays in his own country at time $t$ is given by:

$$
u_{i i, t}=\ln \left(w_{i, t}\right)+A_{i, t}+\varepsilon_{i, t}
$$

where $w_{i, t}$ is the (expected) wage at home; $A_{i, t}$ denotes country $i$ 's characteristics (amenities, public expenditures, social benefits and other push or pull factors) and $\varepsilon_{i, t}$ is a iid extreme-value distributed random term. The utility related to migration from country $i$ to country $j$ at time $t$ is given by:

$$
u_{i j, t}=\ln \left(w_{j, t}\right)+A_{j, t}-C_{i j, t}(.)+\varepsilon_{j, t}
$$

where $A_{j, t}$ denotes country $j$ 's characteristics and $C_{i j, t}($.$) denotes the total bilateral$ cost from moving from $i$ to $j$ at time $t$. The $C_{i j, t}($.$) includes different types of costs :$

$$
C_{i j, t}=c\left(x_{i}, x_{j}, x_{i j}, x_{i t}, x_{j t}, x_{t}, x_{i j t}\right)
$$

The cost function is supposed to be separable (i) into time-invariant origin country factors $\left(x_{i}\right)$ such as being an island, being landlocked, time-invariant destination country factors $\left(x_{j}\right)\left(\right.$ ii) country-pair specific and time-invariant costs $\left(x_{i j}\right)$ that include for

\footnotetext{
${ }^{5}$ The potential list of omitted factors depends on the set of fixed effects. If origin-time and destinationtime fixed effects are included as in our benchmark regression model, these omitted factors are necessarily dyadic and varying over time. Prominent examples of these omitted factors are cultural proximity or bilateral immigration policies. While these can be correlated with networks, their time variability is quite limited and their influence is well captured by time invariant variables such as distance or linguistic proximity. In that respect, Beine and Parsons (2015) include a measure of bilateral policies through the requirement of a visa between the two countries. The estimated elasticity remains virtually identical.
} 
instance linguistic proximity or bilateral migration policies that are constant over the period under investigation, (iii) time-varying origin country factors $\left(x_{i t}\right)$ that include for instance unemployment benefits at origin or human capital level of the sending country, (iv) time-varying destination specific factors $\left(x_{j t}\right)$ such as unilateral immigration policies and finally $(\mathrm{v})$ time-varying pair-specific factors $x_{i j t}$. The specific focus on the network effect falls into that particular category of costs.

Let $N_{i, t}$ be the size of the native population in country $i$ at time $t$. When the random term follows an iid extreme-value distribution, we can apply the results in McFadden (1974) to write the probability that an agent born in country $i$ will move to country $j$ as:

$$
\operatorname{Pr}\left[u_{i j, t}=\max _{k} u_{i k, t}\right]=\frac{N_{i j, t}}{N_{i, t}}
$$

where $N_{i j, t}$ is the number of migrants in the $i$ - $j$ migration corridor at time $t$. Similarly, $N_{i i, t}$ stands for the proportion of workers remaining in their country of origin during period t. See Beine et al. (2011) or Beine et al. (2015a) for further details. This leads to the following estimable equation:

$$
\ln \left(\frac{N_{i j, t}}{N_{i i, t}}\right)=\ln \left(\frac{w_{j, t}}{w_{i, t}}\right)+A_{j, t}-A_{i, t}-C_{i j, t}(.)
$$

The equilibrium relationship makes clear that we need to estimate the bilateral flows as a function of the number of natives from country $i$ staying put, the network, the wage differential, covariates capturing the time-varying push and pull factors as well as additional variables that are supposed to impact the migration costs $C_{i j, t}$. The exact observable variables to include also depend on the choice of fixed effects.

\section{Econometric Estimation}

\subsection{Estimable equations}

Starting from equation (4), we estimate the network impact using two specifications. In both specifications, thanks to the panel dimension, we include destination-time fixed effects $\alpha_{j, t}$. These fixed effects perfectly capture the role of destination specific variables that are either observable or unobservable to the econometrician. Among the latter ones, there are important factors such as variables capturing the evolution of immigration policies. The unavailability of data capturing time-varying immigration policies that are comparable across countries for a large set of destinations is something well known in the migration literature. ${ }^{6}$ The inclusion of $\alpha_{j t}$ makes the inclusion of $w_{j, t}$ unnecessary. Also, these fixed effects capture the role of the following costs components $c\left(x_{j}\right), c\left(x_{t}\right)$ and $c\left(x_{j, t}\right)$.

The specification of the $C_{i j, t}($.$) component plays a key role in the analysis. In our$ preferred specification, we will also include $\alpha_{i t}$ fixed effects so we do not have to worry about the $c\left(x_{i}\right)$ and $c\left(x_{i, t}\right)$ neither. The remaining component of the cost function $c\left(x_{i j, t}\right)$ will be captured by the migrants network $Z_{i j, t}$. The network corresponds to the number

\footnotetext{
${ }^{6}$ The IMPALA project aims at filling this gap. See www.imapala.lu.
} 
of individuals coming from $i$ and living in country $j$ at the start of period $t$. It is nothing else than the diaspora living at the start of the ten-year period during which the flow of new immigrants from $i$ to $j$ will be observed $\left(N_{i j, t}\right)$. We also need to capture the $c\left(x_{i j}\right)$ component, i.e. the time-invariant factors that are specific to the country pair $i j$. To that purpose, we include four observable variables: the geographic distance $d_{i j}$ between the two countries, the existence of a common official language $l_{i j}$, the existence of a common border $b_{i j}$ and the existence of a colonial link $c o l_{i j}$ that was still prevailing after World War II.

We propose two specifications that differ from the exact fixed effects specific to the origin countries. In the first one, we include only origin fixed effects $\alpha_{i}$ that capture only the time-invariant factors such as geographical factors, the size of the country etc ... . This specification allows the inclusion of observable origin and time-varying covariates such as the average wage level at origin (denoted by $w_{i, t}$ ) which is known to play an ambiguous role. The estimable equation takes the following form:

$$
\ln \left(N_{i j, t}\right)=\alpha_{0}+\alpha_{1} \ln \left(w_{i, t}\right)+\alpha_{2} \ln \left(Z_{i j, t}\right)+\alpha_{3} \ln \left(d_{i j}\right)+\alpha_{4} l_{i j}+\alpha_{5} b_{i j}+\alpha_{6} c_{i j}+\alpha_{i}+\alpha_{j t}+\epsilon_{i j t}
$$

where $\epsilon_{i j t}$ is an error term which is supposed to be i.i.d.

In the second one, we include origin-time fixed effects. These origin-time fixed effects allow to have a better specification than the previous one for a set of different reasons. First, as made clear by Beine and Parsons (2015), the use of origin-time fixed effects allows to account for the role of important factors such as immigration policies. The literature has been plagued by the absence of cross-country databases on immigration policies that can be used in gravity models of migration such as (4). Second, the introduction of $\alpha_{i t}$ allows to capture the role of $N_{i i, t}$ in the equilibrium equation (4). This term captures the flow of natives staying in their own country instead of moving abroad. This quantity is very often difficult to observe since it requires to have information about population, all emigration and all immigration flows. 7 The last main reason is that this specification is fully able to account for the issue of multilateral resistance to migration. The concept multilateral resistance to migration (MRM) put forward by some authors including Bertoli and Fernandez-Huerta-Moraga (2013) implies that any shock occurring to another pair (such as a decrease in the bilateral migration cost) has implications for the flow of the pair under interest. Failure to account for that in gravity models of trade or migration might lead to biased estimates of the key elasticities, including the network elasticity $\alpha_{2}$ which is our main coefficient of interest here. The inclusion of both origin-time fixed effects $\alpha_{i t}$ and destination-time fixed effects $\alpha_{j t}$ makes sure that MRM both at origin and at destination is accounted for. ${ }^{8}$ The estimable equation with both types of fixed effects is the following one:

$$
\ln \left(N_{i j, t}\right)=\alpha_{1} \ln \left(Z_{i j, t}\right)+\alpha_{2} \ln \left(d_{i j}\right)+\alpha_{3} l_{i j}+\alpha_{4} b_{i j}+\alpha_{5} \operatorname{col}_{i j}+\alpha_{i t}+\alpha_{j t}+\epsilon_{i j t}
$$

\footnotetext{
${ }^{7}$ See Beine and Parsons, 2015 about that.

${ }^{8}$ In that respect, our estimations allow to see to what extent the ones done in Beine and Parsons (2015) are robust to the inclusion of a MRM term accounting for MRM at origin.
} 


\subsection{Data}

In this paper, we use the same data as in Beine and Parsons (2015). The network variable $Z_{i j, t}$ is the bilateral migrants stocks at the start each decade (1960, 1970, 1980 and 1990). This bilateral stock captures the number of individuals born in country $i$ and living in country $j$. The bilateral stocks are drawn from the database of Ozden et al., 2011. They are based on the population censuses reported in the destination countries and provide a comprehensive measure of the migration stocks at the world level and over a significant period of time. Given the purpose of the paper, we favour this data. Alternative measures have been proposed, for instance emphasizing the consistency of the migration flows across countries (Abel and Sander, 2014). They nevertheless do not span a very long period of time, which prevents the assessment of the evolution of the network elasticity over time.

Our key dependent variable is the dyadic flow $N_{i j, t}$ and is computed from the difference in the stock between $t$ and $t+1$. While this macro measure is straightforward and intuitive, there are nevertheless a couple of issues to pay attention to. These have been emphasized in Beine and Parsons (2015). One issue is the possible negative values for some bilateral flows. This might occur for instance as a result of massive return migration over a period of time. One proposed adjustment is to set negative gross flows to zero. Another one is to add the negative flows to the opposite gross flows. We adopt the first approach. Beine and Parsons (2015) show nevertheless that their results are robust to both approaches.

The measures of the time-invariant dyadic cost variables $l_{i j}, c o l_{i j}, b_{i j}$ and $d_{i j}$ comes from the CEPII database. The wage level $w_{i, t}$ is proxied by the level of gdp per head, draw from the Penn world tables and refined by Gleditsch (2002).

\subsection{Benchmark Results}

Table 1 gives the estimates for the key network elasticity for both specifications and using two popular estimations methods for the full sample of origin and destination countries. Following the empirical literature, we use first Poisson estimations that are supposed to be the best estimation technique in case of many zeroes for the dependent variable (see Santos Silva and Tenreyro, 2006). ${ }^{9}$ We also use scaled OLS, i.e. panel estimations with fixed effects and with the dependent variable expressed as $\ln \left(1+N_{i j, t}\right)$ instead of $\ln \left(N_{i j, t}\right)$ to avoid the selection bias due to the drop of the country pairs with zero migration flows. The scaled OLS estimator does not account nevertheless for the bias arising due to the presence of heteroscedasticity in the error term and is proposed for the sake of some robustness assessment. The Poisson estimations should be more reliable but involve nevertheless a different sample due to the drop of some fixed effects. ${ }^{10}$

Table 1 suggests that if we consider the whole migration process, the network elasticity

\footnotetext{
${ }^{9}$ This applies here since, depending on the sample period, we observe between 47 and $62 \%$ of zeroes for the dependent variable.

${ }^{10}$ It should be nevertheless emphasized that the PPML estimator is not the only possible estimator in presence of zero values for the dependent variable. Alternative Poisson-related estimators such as the zero-inflated Poisson or the negative binomial can be used in that context. Burger et al. (2009) apply these estimators to gravity models of trade flows. These estimators implicitly assume that there are two kinds of zeroes for the dependent. While this is clearly consistent with trade models with explicit distinctions between the intensive and the extensive margin, it is nevertheless unclear how it applies to international migration.
} 
lies between 0.36 and 0.48 . It means that 100 additional migrants in the existing diaspora attract on average between 36 and 48 additional people over the next 10 years. In particular, the estimated elasticity of 0.48 from the "best" specification and using the "best" method can be compared to the one obtained by Beine and Parsons (2015) which amounts to about 0.40. Nevertheless, the many origin and time varying covariates that were introduced in Beine and Parsons (2015) led to a reduction of the sample which leads to about half of the number of observations compared to this one. All in all, this gives a similar order of magnitude and suggests that the impossibility of accounting for MRM at origin in Beine and Parsons (2015) did not affect too much the estimation of the network elasticity.

Table 1: Network effect in international migration: benchmark case

\begin{tabular}{l|cc|cc}
\hline \hline Estimation Method & \multicolumn{2}{|c|}{ Poisson } & \multicolumn{2}{c}{ Scaled OLS } \\
Variables & $(1)$ & $(2)$ & $(3)$ & $(4)$ \\
\hline Network & $0.457^{* * *}$ & $0.479^{* * *}$ & $0.360^{* * *}$ & $0.374^{* * *}$ \\
& $(0.023)$ & $(0.017)$ & $(0.005)$ & $(0.004)$ \\
Income at origin & -0.132 & - & 0.002 & - \\
& $(0.114)$ & & $(0.015)$ & \\
$\ln ($ Distance $)$ & $-0.651^{* * *}$ & $-0.678^{* * *}$ & $-0.312^{* * *}$ & $-0.270^{* * *}$ \\
& $(0.060)$ & $(0.044)$ & $(0.009)$ & $(0.007)$ \\
Language & $0.229^{* * *}$ & $0.359^{* * *}$ & $0.233^{* * *}$ & $0.214^{* * *}$ \\
& $(0.082)$ & $(0.070)$ & $(0.015)$ & $(0.013)$ \\
Contiguity & $0.351^{* * *}$ & $0.179^{* * *}$ & $0.315^{* * *}$ & $0.412^{* * *}$ \\
& $(0.133)$ & $(0.089)$ & $(0.088)$ & $(0.082)$ \\
Colonial links & $0.268^{*}$ & 0.179 & $0.537^{* * *}$ & $0.785^{* * *}$ \\
& $(0.147)$ & $(0.113)$ & $(0.130)$ & $(0.119)$ \\
\hline Origin-time FE $\left(\alpha_{i t}\right)$ & No & Yes & No & Yes \\
Origin FE $\left(\alpha_{i}\right)$ & Yes & No & Yes & No \\
Destination-time FE $\left(\alpha_{j t}\right)$ & Yes & Yes & Yes & Yes \\
\hline \# observations & 122541 & 165571 & 140833 & 189224 \\
$R^{2}$ & 0.789 & 0.930 & 0.532 & 0.511 \\
\hline Columns 1 and 3: equation $(5)$.Estimation period: 1960-2010. \\
Columns 2 and 4: equation $(6)$.Estimation period: 1960-2010. \\
Superscripts ***, **, * denote statistical significance at 1, 5 and 10\% respectively. \\
Robust standard errors are provided in parentheses. \\
$R^{2}$ refers to either pseudo- $R^{2}$ in Poisson regressions or true $R^{2}$ in scaled OLS regressions. \\
\hline \hline
\end{tabular}

\subsection{Sample-specific estimations}

The estimated network elasticities provided in Table 1 provides an interesting assessment of the strength of the network effect at the world level. Nevertheless, such estimations hide the fact that network effects differ in many dimensions. Here, we favour an extension of these estimations in two meaningful directions. First, we make a distinction 
between destination countries in terms of level of development. We distinguish whether the destination country is an advanced economy (captured by OECD membership) or in contrast a less advanced one. It is well established that advanced destination countries receive proportionally more skilled immigrants than less advanced economies (Docquier and Rapoport, 2012). So by making a distinction in terms of destination, we implicitely select global flows of more skilled workers and less skilled workers.

The rationale of doing the distinction in terms of education skills is that the two main components of the network effect (the so-called assimilation effect and the policy effect) depends on the level of income and the level of education of the migrants. Concerning, the assimilation effect, it is well-known that unskilled prospective migrants rely more on the network than skilled migrants (see Beine et al., 2011 among others). For the policy effect, the effect is slightly more ambiguous. On the one hand, unskilled migrants will rely more on family reunification schemes since it is more difficult for them to use the economic channels of immigration policies. ${ }^{11}$ On the other hand, if immigration policies discriminate between unskilled and skilled migrants, or between advanced countries and less advanced countries in terms of origins, it might be the case that the family reunification schemes will be less generous for unskilled migrants coming from developing countries. All in all, we should expect that the key network elasticities should be higher for the migrants coming from the less advanced countries, although the magnitude of the discrepancy remains difficult to grasp before estimation.

The second source of heterogeneity is the time period over which the elasticity is estimated. Here, two considerations have to be made. First, diasporas have been growing over time all over the place. The size of the Mexican diaspora in the US was less than 1 million in 1960, while nowadays, this diaspora amounts to more than 15 millions if you include illegal migrants. Concerning the assimilation component of the network effect, as stressed by Munshi (2014), the marginal effect of one additional existing individual in the diaspora is likely to be non linear in the size of this diaspora. The higher the size, the less likely a prospective migrant will have on average a personal tie with a given individual in the network. Also, it might be the case that in a large diaspora, individuals will care less about the new incoming immigrants of their own country. This calls for a decreasing marginal network effect in the size of the diaspora. The second component relates to the evolution of the family reunification policies at destination. Worldwide, in absence of any reliable measure, it is difficult to know whether the family reunification policies have become more or less generous over time. There is a presumption that in the 80's and the 90's, these policies became more generous as reflected by the US immigration policy (See Appendix). Nevertheless, it is debatable whether the US policy was reflecting or not a global trend across the main destinations. There is also a presumption that in the 2000's and over the recent years, the family reunification policies have become more restrictive, especially for unskilled migrants, as reflected by the French reform of immigration policy ("Immigration choisie") in 2006. But once again, it is unsure whether the French case is idiosyncratic or not. At the end of this paper, in order to shed some light on this,

\footnotetext{
${ }^{11}$ In demand driven system like H1B and $\mathrm{H} 2 \mathrm{~B}$ visas in the US, the likelihood of getting a job offer will be lower for unskilled migrants or the ones coming from far away developing countries. In supply driven systems such as the point systems that are prevailing in the UK and some of its dominion countries (Australia, New Zealand or Canada), the likelihood of reaching the threshold level increases with education.
} 
we will review very briefly some cases in terms of family reunification. This will reflect the complexity to know beforehand how these policies have evolved over time and have actually affected the inflows of immigrants. In turn, this implies the need to estimate from the data the key network elasticities and how they evolve across time and across countries.

Table 2 provides the key elasticities for different subsamples. First we make a distinction between advanced and less advances countries as destinations. Second, we make a distinction between estimates coming from the full period of time (1960-2000), and two subperiods (60's-70's and 80's-90's). In order to save space, we provide only the estimations with Poisson Maximum Likelihood and do not report scaled OLS estimations. ${ }^{12}$

Table (2) provides some interesting insights about the evolution of network elasticities across countries and over time. First, the estimations show that the migrants going to OECD countries rely less on the network, compared to those going to less advanced countries. This is partly explained by the variation of network elasticities across education levels. To the extend OECD countries tend to receive a much higher proportion of skilled workers, the estimates confirm that the assimilation effect is higher for unskilled workers than for skilled ones. Beine et al. (2011) find that the assimilation effect represents for the US about $2 / 3$ of the total network effect. Therefore, variations in that component across education levels is likely to have a major impact on the global estimate.

Second, for all sub-samples, the estimates suggest that the network effect has increased over time. The discrepancy in the network elasticity between the first sub-period (before 1980 ) and the second one (80's and 90's) varies between $27 \%$ and $47 \%$, which is not negligible. This tends to confirm that more generous family reunification policies, not only in OECD countries but also all over the world, tended to make the network effect larger over time. This could have more than offset the decrease in the assimilation effect that goes with the increase of the size of the diaspora.

In the appendix, we review a couple of immigration policies in terms of family reunification to check whether this interpretation makes sense. To that purpose, we cover quickly seven countries: the US, France, Switzerland, Luxembourg and Germany as well as the Netherlands and the UK in a very sketchy way. Although this is very partial, we find that for countries such as the US and Switzerland tended to become more generous in general. For the remaining EU countries, the situation is slightly less clear. On the one hand, there is some evidence that for non EU migrants (so called third country nationals-TCN), the conditions of family reunification have become harder, especially after 2000. On the other hand, with the European unification process, the conditions for family members sponsored by a EU citizen have been less restrictive. Also, like in France and Luxembourg, the conditions for some categories of workers such as highly skilled workers have been relaxed and some discrimination between targeted immigrants has been introduced in these policies. Overall, it is hard without explicit data on immigration policies by category of migrants to isolate a clear trend in the family reunification policies over the world.

\footnotetext{
${ }^{12}$ These are available upon request.
} 
Table 2: Network effect in international migration: sample specific estimates

\begin{tabular}{l|cc|ccc|ccc}
\hline \hline Estimation Method & \multicolumn{2}{|c|}{ All destinations } & \multicolumn{3}{|c|}{ Advanced destinations } & \multicolumn{3}{c}{ Less advanced destinations } \\
Period & 60's-70's & $80^{\prime}$ 's-90's & Full & 60 's-70's & 80 's-90's & \multicolumn{2}{c}{ Full } & \multicolumn{2}{c}{60 's-70's } & $80^{\prime}$ 's-90's \\
\hline Variables & $(1)$ & $(2)$ & $(3)$ & $(4)$ & $(5)$ & $(6)$ & $(7)$ & $(8)$ \\
\hline Network & $0.415^{* * *}$ & $0.530^{* * *}$ & $0.380^{* * *}$ & $0.337^{* * *}$ & $0.428^{* * *}$ & $0.514^{* * *}$ & $0.404^{* * *}$ & $0.588^{* * *}$ \\
& $(0.028)$ & $(0.016)$ & $(0.023)$ & $(0.049)$ & $(0.005)$ & $(0.017)$ & $(0.029)$ & $(0.017)$ \\
$\ln$ (Distance) & $-0.878^{* * *}$ & $-0.535^{* * *}$ & $-0.747^{* * *}$ & $-0.826^{* * *}$ & $-0.685^{* * *}$ & $-0.788^{* * *}$ & $-1.217^{* * *}$ & $-0.497^{* * *}$ \\
& $(0.072)$ & $(0.046)$ & $(0.081)$ & $(0.115)$ & $(0.098)$ & $(0.050)$ & $(0.097)$ & $(0.044)$ \\
Language & $0.430^{* * *}$ & $0.246^{* * *}$ & $0.588^{* * *}$ & $0.553^{* * *}$ & $0.474^{* * *}$ & $0.295^{* * *}$ & $0.430^{* * *}$ & $0.214^{* * *}$ \\
& $(0.129)$ & $(0.072)$ & $(0.125)$ & $(0.203)$ & $(0.137)$ & $(0.086)$ & $(0.171)$ & $(0.081)$ \\
Contiguity & $0.531^{* * *}$ & 0.001 & 0.077 & $0.484^{*}$ & -0.333 & 0.062 & $0.2933^{* * *}$ & 0.041 \\
& $(0.157)$ & $(0.083)$ & $(0.223)$ & $(0.271)$ & $(0.241)$ & $(0.069)$ & $(0.164)$ & $(0.058)$ \\
Colonial links & $1.029^{* * *}$ & -0.224 & $0.255^{*}$ & $1.301^{* * *}$ & $-0.370^{*}$ & 0.134 & $0.766^{* * *}$ & -0.067 \\
& $(0.159)$ & $(0.136)$ & $(0.154)$ & $(0.219)$ & $(0.205)$ & $(0.146)$ & $(0.310)$ & $(0.152)$ \\
\hline Destination-time FE $\left(\alpha_{j t}\right)$ & Yes & Yes & Yes & Yes & Yes & Yes & Yes & Yes \\
Origin-time FE $\left(\alpha_{i t}\right)$ & Yes & Yes & Yes & Yes & Yes & Yes & Yes & Yes \\
$\#$ observations & 83762 & 81809 & 20832 & 10416 & 10416 & 144739 & 73346 & 71393 \\
$R^{2}$ & 0.910 & 0.956 & 0.907 & 0.821 & 0.936 & 0.970 & 0.966 & 0.986 \\
\hline
\end{tabular}

Estimated equation: equation (6).Poisson ML estimates.

Superscripts $* * *, * *, *$ denote statistical significance at 1,5 and $10 \%$ respectively.

Robust standard errors are provided in parentheses. $R^{2}$ refers to pseudo- $R^{2}$. 


\section{Conclusion}

This paper reviews the recent existing literature on the network effect in international migration. We argue that both micro and macro approaches are needed to get a deeper understanding of the main mechanisms behind the global network effect. The main components of this effect are threefold : (i) the reduction in assimilation costs, (ii) the benefits in terms of wage conditions and employment and (iii) the policy effect going through the family reunification policy. While the micro literature have shed some light on the first two components, the macro estimates of the network elasticity allow to have an assessment of the global effect and hence the third component.

We provide an update of the network elasticity with respect to the existing macro literature. We use the migration data of Ozden et al. (2011) over the 1960-2000 period and reestimate the network effects using a specification that fully controls for the issue of multilateral resistance to migration. We find overall an elasticity slightly less than 0.5 , meaning that on average a $10 \%$ increase in the existing stock of migrants from a given origin country tends to increase the bilateral flow from that country by $5 \%$. This elasticity is in line with the recent estimate of Beine and Parsons (2015) using the same data. We then looked at the variation across types of destinations and over time. Our results confirm that the network effect in advanced receiving countries is less important. This might be ascribed to the fact that these countries tend to host a higher proportion of skilled migrants who rely less on the network.

We also find that the network effect has increased over time. This might be related to the fact that the family reunification policies in the 80's and 90's became more generous worldwide. In absence of existing data on these policies, it is hard to know whether it is actually the case. A quick coverage of seven destination countries suggests that these policies exhibit different trends. While the family reunification policies for the US and Switzerland tended to become more generous in general, this trend is not observed in the Continental European countries such as France, Germany and Luxembourg for migrants coming from outside the EU, at least over the recent period of time. Nevertheless, these countries receive a large proportion of migrants coming from the EU, for which the conditions of family reunification have become less restrictive over time. Overall, this advocates in favour of the development of data capturing immigration policies by category of immigrants. 


\section{References}

Abel , G. and N. Sander (2014), Quantifying Global International Migration Flows, Science, 343, 1520-1522.

Anderson, J. (2011), The gravity model, Annual Review of Economics, vol. 3, 133-160.

Ariu, A. , F. Docquier, M. and M.P. Squicciarini (2014). Governance Quality and Net Migration Flows, mimeo, University of Louvain.

Batista, C. and G. Narciso (2013), Migrant Remittances and Information Flows: Evidence from a Field Experiment, IZA Discussion Paper 7839.

Beine, M., S. Bertoli and J. Fernandez-Huertas Moraga (2015a). A practitioners' guide to gravity models of international migration. World Economy, forthcoming.DOI: $10.111 /$ twec. 12265 .

Beine, M. and P. Bourgeon and J-C. Bricongne (2013),Aggregate Fluctuations and International Migration, CESifo Working Paper No. 4379 .

Beine, M., F. Docquier, C. Özden (2011). Diasporas. Journal of Development Economics, 95 (1), 30-41.

Beine, M., F. Docquier, C. Ozden (2015b). Dissecting network externalities in international migration, Forthcoming in the Journal of Demographic Economics.

Beine, M. and C. Parsons (2015), Climatic Factors as Determinants of International Migration, Scandinavian Journal of Economics, 117, 723-767.

Bertoli, S., and J. Fernandez-Huertas Moraga (2013): Multilateral Resistance to Migration, Journal of Development Economics, 102, 79-100.

Bertoli, S. and J. Fernandez-Huertas Moraga (2015). Visa Policies, Networks and the Cliff at the Border. Regional Science and Urban Economics, 51,1-6.

Blinder, S. (2015),Non-European Migration to the UK: Family and Dependents, Briefing, The Migration Observatory at the University of Oxford, January.

Bin, Yu (2007). Chain Migration Explained: The Power of the Immigration Multiplier. LBF Scholar Publishing: El Paso, U.S.

Burger, M., F. van Oort and G. Linders (2009), On the Specification of the Gravity Model of Trade: Zeros, Excess Zeros and Zero-Inflated Estimation, Spatial Economic Analysis, 4 (2), 167-190.

Carrington, W.J:, E: Detragiache and T. Wishwanath (1996), Migration with Endogenous Moving Costs, American Economic Review, 86 (4), 909-930.

Comola, M. and M. Mendoza (2015), Formation of Migrants' Network, Scandinavian Journal of Economics, 117 (2), 592-618.

Czaika, M. and C. Parsons (2015). The Gravity of High Skilled Migration Policies, Mimeo, Oxford university.

Docquier, F. , and H. Rapoport (2012), Globalization, Brain Drain and Development, Journal of Economic Literature, 50 (3), 681-730.

Giulietti, C., J. Wahba and Y. Zenou (2014), Strong versus Weak Ties in Migration, IZA Discussion paper 8089.

Gleditsch, K. S. (2002), Expanded Trade and GDP Data, Journal of Conflict Resolution, 46, 712724 .

Grogger, J. and G.H. Hanson (2011), Income maximization and the selection and 
sorting of international migrants, Journal of Development Economics, 95(1), 4257.

Jasso, G. and M. R. Rosenzweig (1986). Family Reunion and the Immigration Multiplier: U.S. Immigration Law, Origin-Country Conditions, and the Reproduction of Immigrants. Demography 23 (3), 291-311.

Jasso, G. and M. R. Rosenzweig (1989). Sponsors, Sponsorship Rates and the Immigration Multiplier. International Migration Review 23 (4), 856-888.

Kerr, W. and M. Mandorff. 2015. Social Networks, Ethnicity, and Entrepreneurship, National Bureau of Economic Research, Working Paper 21597.

Mahuteau, S. and P. Junankar (2008), Do Migrants Succeed in the Australian Labour Market ? Further Evidence on Job Quality, MRPA Paper, 8703.

Massey, D. S., J. Arango, G. Hugo, A. Kouaouci, A.Pellegrino and J. E. Taylor (1993). Theories of international migration: Review and Appraisal. Population and Development Review 19 (3), 431-466.

McFadden, D.L. (1974), Conditional Logit Analysis of Qualitative Choice Analysis, in Frontiers in Econometrics, Ed. P.Zarembka, New York: Academic Press, 105-142.

McKenzie, D., J. Gibson and S. Stillman (2013), A Land of Milk and Honey with Streets Paved with Gold: Do Emigrants have Over-optimistic Expectations about Incomes Abroad?, Journal of Development Economics, 102, 116-127.

McKenzie, D., H. Rapoport (2010). Self-selection patterns in Mexico-US migration: the role of migration networks. Review of Economics and Statistics, 92 (4), 811-821.

Munshi, K. (2003).Networks in the Modern Economy: Mexican Migrants in the U.S. Labor Market. Quarterly Journal of Economics 118 (2), 549-99.

Munshi, K. (2014). Community Networks and Migration, mimeo, University of Cambridge.

Özden, C., C. Parsons, M. Schiff, and T. Walmsley, (2011) Where on Earth is Everybody? The Evolution of International Bilateral Migration 1960-2000, World Bank Economic Review, 25(1), 12-56.

Oliver, C. (2013), The Impact of Restrictions and Entitlements on the Integration of Family Migrants: a Comparative Report, Compass, University of Oxford, October 2013.

Patel, K., and F. Vella. 2013. Immigrant Networks and Their Implications for Occupational Choice and Wages, Review of Economics and Statistics, 95(4), 1249-77.

Santos Silva, J. M. C. and Tenreyro, S., 2006. The Log of Gravity. Review of Economics and Statistics, 88 (4), 641-658.

Simon, H., R. Ramos and E. Sanroma (2014), Immigrant Occupational Mobility: Longitudinal Evidence from Spain, European Journal of Population, 30 (2), 223-255. 


\section{Appendix: a quick review of the family reunifica- tion policies in a set of destination countries}

In this appendix, we review a couple immigration policies in terms of family reunification. We cover quickly four countries: the US, France, Switzerland, Luxembourg, Germany, the Netherlands and the UK. This review intends to give a broad overview of the evolution of these policies and does not intend to provide a full review of the numerous changes that have taken place over the recent period.

\subsection{United States}

The evolution US immigration policy is characterized by the passing of successive immigration Acts. The 1924, 1952, 1965 and 1990 Immigration Acts paved the way for the main evolutions of the system. Until 1965, the US immigration policy was subject to an origin quota system that limited the entrance of immigrants by country. The policy had also introduced a hierarchy of family-based preferences. As a matter of fact, the policy was quite restrictive for large and non-European origin countries that were keen to rely on family reunification. The 1965 Act abolished the national origin quota system but introduced a distinction between two main categories of family-based immigrants. The first one comprised immediate relatives of US citizens who were not subject to any numerical restriction. The second one included immigrant relatives of US citizens and relatives of lawful permanent residents and is subject to numerical caps. It also imposed a per country limit on family-based immigrants that limited any single country to have at most $7 \%$ of these immigrants of the statutory total.

In the 80's and 1990's, two main developments are worth to be mentioned. First, the 1986 amnesty led to a de facto increase of family-based immigrants as the legalized immigrants became eligible to bring family members without any restriction in terms of quota. Second, the 1990 increased overall immigration under a global cap. It also increased the annual statutory limit of family-based immigrants from 290000 to 480000. The current prevailing system considers different family sponsored categories that are each subject to annual numerical cap. The system imposed a four-tier system of categories with a ranking in terms of preference limit. Spouses and minor children of US citizens as well as parents of adult U.S. citizens are granted permanent residency without being subject to numerical quotas.

All in all, the whole evolution of the family-based immigration policy in the US suggests that the policy became more generous in the 80's and 90's compared to before. Whether it has become more restrictive afterwards is more unclear.

\section{$7.2 \quad$ France}

In covering the French case which is quite representative of the other European continental countries, it is useful to make two distinctions. First, one needs to make a distinction between migration in terms of accompanying family and migration in terms family reunification. Family reunification, which refers to the migration process of family members initiated by a sponsor who is located in the receiving country is more relevant for the 
family multiplier component of the network effect. Second, it is important to make a distinction between origin countries outside the European Union and those within the European Union. In general, when the sponsor or the family members are from another European country, the conditions are much less restrictive. For instance, since 1998, the stay permit based on private life and family has been automatically granted to EU citizens. We therefore cover mostly the evolution of the general conditions of family reunification applicable to third country nationals (TCN).

The first immigration law in terms of family reunification dates back from 1974 . This decreet attempts to restrict family-based immigration. In 1976, France issued the first legislation giving details on the procedure for family reunification and defining the required conditions in terms of minimum resources, accommodation and minimal duration of previous stay for the sponsor. In 1977, a decreet tried to stop family immigration for 3 years. In the 80's and 90's, in general, the conditions for TCN in France became in general tougher. In 1984, it was forbidden to regularize family members already located in France and explicit conditions about the level of resources, accommodation, health and minimal duration of stay of the sponsor are explicitly defined. In 1993, the partner of a French citizen is no longer granted a stay permit for 10 years. The required minimal duration of stay of the sponsor was increased and tougher conditions in terms of employment of the

sponsor were introduced. Since 1998, the application for family reunification has been subject to a fee.

In the 2000's, in general the conditions were further strengthened. This applies to different sets of conditions : minimal duration of stay of the sponsor (2000), evidence of the community of life for 2 years instead of 1 year (2004), further strengthening of these conditions in 2006 and further increase in the minimal resources of the sponsor depending on the family size (2007). While this coverage is very sketchy and conceals a lot of details, the whole description tends to suggest than since 1974, France has continuously strengthened the conditions under which family reunification is allowed for migrants outside the EU.

\subsection{Luxembourg}

The Luxembourguish case is specific in the sense that before 2008, there was a lack of legal basis for the family reunification process for TCN. After the initial immigration law of 1972 , basically the process was evaluated on a case by case basis by the immigration authorities. These conditions require a stay permit for the sponsor, which in turn requires to have housing and to have worked continuously during two years before. Many migrants coming through family reunification also came from countries such as Portugal and Yugoslavia that had signed bilateral agreements with Luxembourg, allowing to give a legal basis for the conditions of family migration.

In 2008, the law secured the legal basis for family reunification and provided the details about the conditions to be met. These involve to have a stay permit for at least 12 months, and criteria in terms of financial resources, housing and health insurance. It is also worth being noticed that some categories of sponsors such as the highly skilled workers, researchers and corporate transferees have the right to bring the family members immediately (the so-called accompanying family process). This reflects a trend observed in some European countries in terms of discrimination of conditions depending on the 
profile of the sponsor.

\subsection{Switzerland}

Switzerland makes a distinction depending on the origin of the sponsor : TCN, EU/EFTA countries or Swiss national. In the 90's, family reunification with TCN sponsor favoured the migration of spouse and minor child (under 18), with some preferences in terms of conditions for some countries of origin (Italy, Spain, Portugal). The same conditions applied to EU/EFTA countries. Swiss nationals were allowed to attract extended family members (parents or grandparents for instance).

In 2008, for TCN sponsors, the law imposed some restriction in terms of time to exercise the right for TCN sponsors to bring family members ( 5 years for minor children and spouses for instance). On the other hand, family reunification was allowed for sponsors with a permit of stay labelled "study and educational purposes". For sponsors coming from an EU/EFTA country, the Enforcement agreement on Free Movement increased the categories of family members allowed to immigrate. The agreement also increased the possibilities of residence and employment for partners and children up to 21 years.

From the evolution of the immigration law in terms of family reunification, it is cumbersome to assess whether the policy has become more generous over time. Nevertheless, it is quite obvious that the treatment for immigrants coming from EU/EFTA countries became more favourable in the 2000's.

\subsection{Germany}

Like for France, it is important for German family reunification policy to make a distinction between TCN sponsors and those coming from another European member state. The peculiarity in the German policy is the distinction between first and second generation TCN migrants as sponsors. In general, in the 90's and early 2000's, the prevailing conditions were fairly standard, with requirements that the sponsors holds a residency permit, has sufficient income and housing to host the family members. For the second generation migrants, the requirement in terms of duration of establishment in Germany was 8 years. During the 1990's and 2000's, for TCN sponsors, the conditions were slightly relaxed, with the existence of family income not relying exclusively on the sponsor (1997) and the categories of eligible family members slightly extended (2000). With the reform in 2005, the distinction between first and second generation migrants was abolished.

As documented by Oliver (2013), the recent evolution of the family reunification policies follows the trends observed in other European countries such as the Netherlands and the UK (see below). More restrictive policies were implemented around 2005-2006 such as new pre-entry conditions of the German language skills for prospective family migrants. These policies resulted in a significant decrease of annually granted family visas between 2002 (85305) and 2011 (40975). 


\subsection{Other European countries}

Oliver (2013) covers the situation of four European countries in terms of admission policies for family migrants. The overview makes part of the IMPACIM project that aims at providing quantitative measures of those polices. We simply refer to the main conclusions in terms of variation over time of the stringency of the family reunification policies in place in these countries. Nevertheless, Oliver (2013) covers the recent period, starting mainly after 2000, while our estimation period refers to a comparison between the situation prevailing in the 60's and 70's versus the one in the 80's and 90's. We do not comment on the situation prevailing in Spain as the family migrants represented a very small proportion of migrants before 2000 and as the surge in immigration occurred after 2000 was clearly dominated by labour migration.

In the Netherlands, the general perception is that the reunification process was quite easy for prospective family migrants up to the end of the 80's. The automatic character of the process derived from the human rights perspective of the family reunification philosophy. More restrictive policies were introduced in the 90's and 2000's as policy makers saw increasingly family migration more as a problem. Pre-entry policies were introduced and more demanding integration policies were implemented. Conditions of access to public assistance were increased for family migrants as well as the length of their requested dependence on the sponsor. These restrictive policies were targeted towards the immigrants of the main diasporas (Turkey and Morocco). The perception of more restrictive policies is in line with a decrease of the number and the share of family migrants between 2004 and 2008.

The UK also tended to put more restrictive policies in the 2000's, as a result of the large increase of the number of family migrants before that period. As documented by Blinder (2015), according to Immigration and Population Statistics estimates, nonEU family migration (from non EU countries) to the UK increased from an average of 35,000 per year in the 1990s to about 50,000 in 2000 and peaking at 74,000 in 2006 . The increasingly restrictive policies were reflected in a decreased to the number of visas granted for family reasons to applicants outside the EU. Nevertheless, it should be noticed that family migrants from EU and non EU countries are nowadays more or less at the same level as the one that prevailed in the 90's. 